international non-governmental organisations providing emergency relief in Lebanon should work closely with local health providers to rebuild services and plan for longer term care. Working in partnership with local communities will help expand affordable health care coverage, encourage retention of the workforce, promote resiliency, and begin a healing process to a hugely traumatised and dispossessed population.

Contributors and sources: See bmj.com

Competing interest: None declared.

1 Ammar W, Azzam O, Khoury R, Fakha H, Mattar C, Halabi M, et al. Lebanon national health accounts 1998. Beirut: Ministry of Public Health in Lebanon, World Health Organization, and World Bank, 2000.
2 Kronfol NM, Bashshur R. Lebanon's health care policy: a case study in the evolution of a health system under stress. J Public Health Policy 1989;10:377-96

3 Van Lerberghe W, Ammar W, el Rashidi R, Sales A, Mechbal A. Reform follows failure. I. Unregulated private care in Lebanon. Health Policy Plan 1997;12:296-311.

4 Mechbel A. Health care reform in Lebanon: research for reform. In: Nitayarumphong S, ed. Health Care Reform at the Frontiers of Research and Policy Decisions. Bangkok: Ministry of Public Health, 1997:120-40.

5 Harik J. The public and social services of the Lebanese militias. Vol 14. Oxford: Centre for Lebanese Studies, 1994.

6 Sibai A-M, Refaat M, Rizk R, Saab R, Saab W, Sabbagh M, et al. The use and overuse of coronary angiography in Lebanon. BMJ (Middle East) 2004;11:6-17.

7 Ammar W. Health system and reform in Lebanon. Beirut: Enterprise Universitaire d'Etudes et de Publication, 2003.

doi $10.1136 /$ bmj. 38996.466678 .68

\title{
Reproductive health of Arab young people
}

\author{
Jocelyn DeJong, Golda El-Khoury
}

Cultural taboos are limiting young people's access to sexual and reproductive services and information

The Arab region, though diverse, is characterised by patriarchal social systems and family structures that give prominence to the role of men in both public and private spheres. Only recently has this situation been challenged by public policies and reforms in family laws. Since the international conference on population and development in Cairo in 1994, governments have pledged to improve the sexual and reproductive health of adolescents by providing integrated health services including contraception for sexually active adolescents and health education. Most regions of the world still fall well short of these recommendations, especially for unmarried young people, but those in Arab countries are particularly underserved. ${ }^{12}$

\section{Demographic changes affecting young people}

Focus on the high percentage of young people in the population has tended to sideline other demographic trends in the region with important implications for young people. These include the large recent rise in the average age at marriage for both sexes (nearing 30 in parts of North Africa ${ }^{3}$ ) and the rising proportions of young unmarried women in many Arab countries. ${ }^{4}$ These trends have occurred in a cultural context where marriage is universally expected and sexuality outside marriage, particularly for women, heavily sanctioned and thus have important ramifications for reproductive health. Although research is very limited, premarital sexual relations are reported; in Jordan, $7 \%$ of college students admitted to non-marital sex in a study in 1994, as did 4\% of the general population aged 15-30 in 1999.5 Among university students in Egypt, $26 \%$ of men and $3 \%$ of women reported having sexual intercourse at least once. ${ }^{6}$

Major changes in the institution of marriage in the region are almost completely unexplored. There has been a resurgence of customary ('urfi) marriage, whereby young people obtain a clandestine marriage certificate to engage in sexual relations but are unprotected legally or in terms of health services, in countries such as Egypt. ${ }^{7}$ Other forms of temporary marriage such as "summer marriages" in Egypt or "business related marriage" in the Gulf countries are increasingly discussed in the Arabic media, but their prevalence is unknown.

\section{Lack of information}

Family life in the region is changing because of migration, urbanisation, busy lives, and new lifestyles brought by the mass media and consumerism. ${ }^{1}$ A rapid increase in access to education and exposure to the global media has widened generational gaps between parents and their children ${ }^{8}$ and altered the ways in which young people receive information. Although studies show that young people would prefer to learn about puberty and their health from their parents, many parents are reluctant or ill equipped to provide this information. A nationally representative survey of young people and their parents in Egypt in the late 1990s found that, although $42 \%$ of fathers reported talking to their adolescent sons about pubertal changes, only $7 \%$ of boys reported learning about puberty from their fathers. ${ }^{9}$

The lack of accurate information about sexuality and reproduction reflects a wider public policy reluctance to provide sex education in schools. Although sex education is increasingly included on curriculums, teachers are often too embarrassed to teach it.

\section{Absence of appropriate health services}

Government health services generally do not recognise the special needs of young people or foster a climate that supports them. As a result, private health services are often the only place where young people can seek help on sexual and reproductive health issues,

Action points are given on bmj.com
Faculty of Health Sciences, American University of Beirut PO Box 11-0236, Riad El Solh, 1107 2020, Beirut, Lebanon

Jocelyn DeJong associate professor

Unicef Middle East and North Africa Region, PO Box 1551, Amman 11821, Jordan Golda El-Khoury regional advisor on youth

Correspondence to: J DeJong jd16@aub.edu.lb

BMJ 2006;333:849-51 


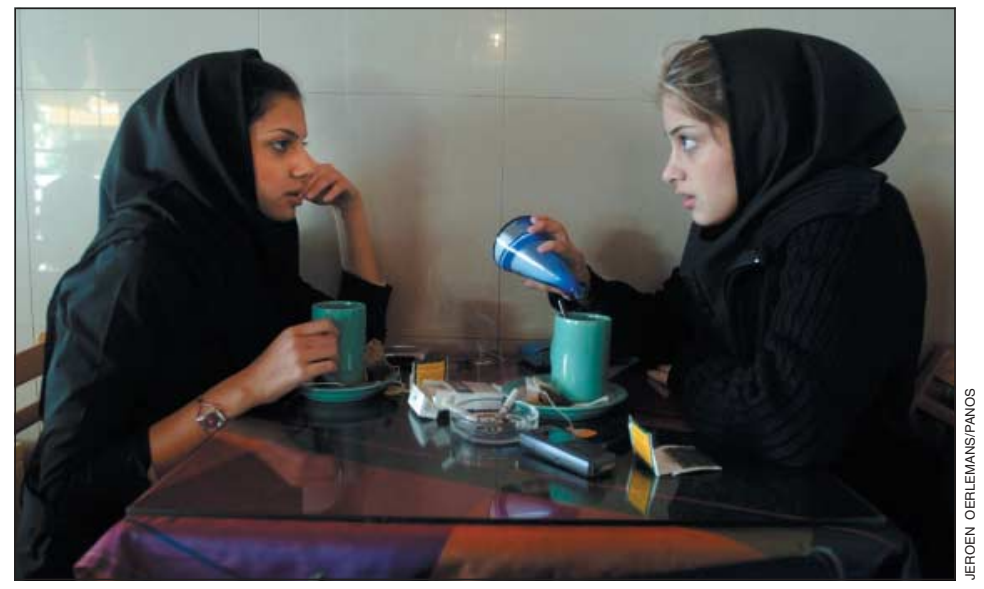

Internet sites promote discussion on sexual health

and even if they can afford these services many social barriers persist. A small qualitative study of Jordanian young people aged 10-24 found that most still equate reproductive health with maternal health care and believe that health centres are exclusively for mothers and babies. ${ }^{10}$ As a 15 year old respondent put it, "If we went to ask a nurse or a doctor, they would laugh at us and tell us to wait till we get older."10

The exception to this trend is Tunisia, which has initiated adolescent health clinics that are open to unmarried young people. It has also established school health clinics in all major towns. These clinics include counselling and information on reproductive health and refer clients to specialised counselling or treatment if necessary. ${ }^{11}$

The high social and religious value placed on virginity means that unmarried young women risk stigma and judgmental attitudes from health workers if they try to obtain contraception. ${ }^{1}$ But young women who marry early also lack knowledge and access to contraceptive services, let alone basic reproductive health services. ${ }^{12}$ They face strong pressures to have children as soon as they are married. In Oman, for example, less than $1 \%$ of women reported using contraception before their first child. ${ }^{13}$ Only Tunisia has legalised abortion on demand, and unsafe induced abortion is reported elsewhere in the region. Emergency contraception is currently licensed in Algeria, Egypt, Lebanon, Libya, Tunisia, and Yemen. ${ }^{14}$ Young people, however, are not widely informed about its availability (A Foster, Ibis Reproductive Health, personal communication).

Almost no systematic data has been collected on young people's awareness of HIV/AIDS or their risk behaviours, despite the fact that internationally half $\%$ of new infections are estimated to occur among young people. Much greater efforts are needed to ensure confidentiality of HIV testing (as Tunisia has done with legislative reform currently under review) and to reduce stigmatisation associated with HIV and AIDS.

\section{Violence and conflict jeopardise reproductive health}

The effects of conflict on the reproductive health of young people are also under-researched. Khawaja found, for example, that during the first uprising against Israeli occupation the age of marriage fell

\section{Summary points}

Arab young people's reproductive health needs are not being fully met due to societal reluctance to address these issues and cultural and religious sensitivities

Health services generally fail to recognise the special needs of this age group, particularly those who are unmarried

Little is known about what young people themselves want in terms of sexual and reproductive health services

Pervasive conflict in the region has grave implications for young people's sexual and reproductive health

Innovative small scale programmes exist that could be built on

among Palestinian women. ${ }^{15}$ In Iraq, political instability after 2003 led to a rise in violence against women, for which services are unprepared. ${ }^{16}$ Civil war has been one of the main drivers of the AIDS epidemic in Sudan, and many cases of sexual and other violence against women in Darfur have been reported.

\section{Promising developments}

Arab young people show ingenuity in communicating, forging relationships, and even tackling some of these controversial topics despite social sanctions and, in some cases, fear of political consequences. New internet sites are becoming accessible to young people that allow them to deal with sexual and reproductive health. ${ }^{17}$ There have also been pressures to reform family laws in ways favourable to women and young people. Countries such as Jordan and Algeria have enacted reforms to raise the legal age at marriage. Morocco and Algeria reformed the family code giving more rights for women in divorce and made it more difficult for men in Morocco to take a second wife. Algeria has recently granted women married to non-Algerians the right to convey their nationality to their children. Some innovative culturally sensitive programmes models could usefully be shared across the region:

- Tunisia, recognising the vulnerability of rural women attending urban universities, introduced a peer education programme on reproductive health in female dormitories ${ }^{18}$

- Several countries, including Egypt and Oman, have confidential anonymous telephone hotlines on sexual and reproductive health and HIV that disproportionately serve young people ${ }^{1920}$

- The Syrian Family Planning Association and Arab Red Crescent recently opened four voluntary AIDS counselling and testing centres targeting 25000 vulnerable young people and 1500 commercial sex workers (I El Daker, HIV/AIDS project officer, Unicef Syria, personal communication) 
- Summer caravans toured Morocco distributing 15000 condoms and providing voluntary and confidential HIV testing and counselling to 7000 young people ${ }^{21}$

\section{The way forward}

Sensitivity surrounding young people's sexual and reproductive health has limited the knowledge base, particularly on young people's perspectives and needs, that could inform legislation, policy, and programmes. Appropriate sex education could be strengthened through working with teachers and parents. Special attention is needed in designing programmes that reach the most vulnerable young people. Above all, government commitment is required to translate the small scale models in the region to national programmes that improve the welfare of all young people.

The statements in this article are the views of the authors and do not necessarily reflect the policies or the views of Unicef.

Contributors and sources: This article draws on a larger study based on a literature review and interviews with 51 informants supported by Unicef's Middle East and North Africa office. ${ }^{1}$ Bonnie Shepard was responsible for the overall design of the study, gave numerous comments, and provided information for the situation analysis. George Ionita and Golda El-Khoury managed the study project and Naheed Aziz reviewed an earlier draft. Julieta LeMaitre reviewed legislation and government commitments. Iman Mortagy and Rana Jawad helped with research.JDJ's research interest is reproductive health and HIV/ AIDS in the Middle East region, GE-K has been active in promoting rights-based multi-sectoral policies and programs on young people in the Middle East and North Africa region. JDJ was author of situation analysis, wrote the article, and is guarantor; GE-K drafted some sections of this article, gave many substantive comments on the text, and provided material on programmes reaching young people.

Competing interests: None declared.

1 Shepard B, DeJong J. Breaking the silence and saving lives: young people's sexual and reproductive health in the Arab States and Iran. Boston, MA: International Health and Human Rights Program, Harvard School of Public Health, 2005.
2 DeJong J, Shepard B, Jawad R, Mortagy I. The sexual and reproductive health of young people in the Arab countries and Iran. Reproductive health of young people in the Arab countries and Iran. Reproductive

3 Fargues P. Women in Arab counties: challenging the patriarchal system? Reprod Health Matters 2005;13(25):43-8.

4 Rashad H, Osman M, Roudi-Fahimi F. Marriage in the Arab world. Washington, DC: Population Reference Bureau, 2005.

5 Johns Hopkins University, Centre for Communication Programs, National Population Commission, Jordan. Jordanian youth survey: knowledge, attitudes and practices on the reproductive health and family planning. Amman:Johns Hopkins University, 2001.

6 El-Zanaty F, El-Daw A. Behavior research among Egyptian university students. Cairo: International Medical Technology Egypt, Family Health International, Behavioral Research Unit, 1996

7 Beamish J. Adolescent reproductive health in Egypt: status, policies, programs and issues. Policy Project, 2003. www.policyproject.com/pubs/ countryreports/ARH_Egypt.pdf (accessed 4 Oct 2006).

8 Fargues P. La génération du changement. Monde Arabe: Maghreb Machrek 2001;171-2:3-11

9 El-Tawila S, Ibrahim B, Sallam S, El Gibaly, O, El Sahn F. Transitions to adulthood: a national survey of Egyptian adolescents. Cairo: Population Council, 1999.

10 Princess Basma Women's Resource Centre. Qualitative research on reproductive health knowledge and needs among Jordanian youth. Amman: Princess Basma Women's Resource Centre, 2000.

11 World Health Organization. Growing in confidence: programming for adolescent health and development. Lessons from eight countries. Geneva: WHO, 2002.

12 Aoyama A. Reproductive health in the Middle East and North Africa. Washington, DC: World Bank, 2001

13 Al Riyami A, Afifi M, Mabrey R. Women's autonomy, education and employment in Oman and their influence on contraceptive use. Reprod Health Matters 2004;12(23):144-55.

14 Foster A, Wynn L, Rouhana A, Polis C, Trussell J. Reproductive health, the Arab world and the internet: usage patterns of an Arabic-language emergency contraception website. Contraception 2005;72:130-7.

15 Khawaja M. The recent rise in Palestinian fertility: permanent or transient? Pop Stud 2000;54:331-46.

16 Human Rights Watch. Climate of fear: sexual violence and abduction of women and girls in Baghdad. Human Rights Watch 2003;15(7).

17 BBC News. Egyptians tackle taboos through net," 2 Sep 2003. http:// news.bbc.co.uk/go/em/fr/-/2/hi/technology/3199007.stm (accessed 4 Oct 2006).

18 Association Tunisienne du Planning Familial. Evaluation du Projet La Double Protection pour les Jeunes': Résultats d'une enquête qualitative auprès des étudiantes dans les foyers universitaires. Résultats d'une enquête qualitative. Tunis: ATPF, 2003.

19 Egyptian Ministry of Health and Population. Report on AIDS Hot-Line 1 January - 31 December 2001. Cairo: MHP, 2002.

20 Oman National AIDS Programme. HIV/AIDS Hotline records. Oman: Ministry of Health, Oman, 2006.

21 UNAIDS. Summer caravan drives forward HIV prevention efforts in Morocco. UNAIDS. Summer caravan drives forward HIV prevention efforts in Morocco.
Press briefing, 4 Sep 2006. www.unaids.org/en/MediaCentre/ PressMaterials/FeatureStory/20060901-morocco.asp (accessed 4 Oct 2006).

doi $10.1136 /$ bmj.38993.460197.68

\title{
HIV in the Middle East
}

\author{
Carla Makhlouf Obermeyer
}

Prevalence of HIV in the Middle East is low but there is no room for complacency

The problem of HIV in the Middle East has elicited contradictory expectations and responses. Denial ("Not in our region") characterised the early phases of the epidemic. HIV was presented as a disease brought from countries where sexual morals were decadent, and obedience to Islam was thought to offer the best protection. ${ }^{1}$ Perhaps as a reaction to this, allegations have been exaggerated that the problem represents a public health crisis concealed "behind the veil." As in earlier debates on Islam and fertility, preconceived notions seem to stand in the way of assessing the situation in light of evidence.

This review summarises what is known about the HIV epidemic in the Middle East and north Africa region and examines the extent to which lower prevalence can be attributed to cultural factors, particularly those related to the practice of Islam and to gender.
The Middle East and north Africa region is defined here as including Arab countries and Iran.

\section{What is the state of the evidence?}

All countries of the Middle East and north Africa compile statistics on reported cases of HIV and AIDS, but case definitions are inconsistent and local capacity for diagnosis and reporting is uneven. Nearly all countries screen blood donors, but epidemiological surveillance is lacking and monitoring of special risk groups is infrequent and at times hampered by local sensitivities. Only a few countries test pregnant women to estimate HIV prevalence in the population. Knowledge,

The search strategy and promising initiatives are on bmj.com
Department of HIV/AIDS, World Health Organization, Geneva, 1211, Switzerland Carla Makhlouf Obermeyer scientist obermeyerc@who.int BMJ 2006;333:851-4 